\title{
ANALYSIS OF AN ANTI-PARALLEL MEMRISTOR CIRCUIT
}

\author{
Valeri Mladenov, Stoyan Kirilov \\ Technical University of Sofia, Faculty of Automatics, Department of Theoretical Electrical Engineering
}

Abstract. The basic purpose of the present paper is to propose an extended investigation and computer analysis of an anti-parallel memristor circuit with two equivalent memristor elements with different initial values of the state variables using a modified Boundary Condition Memristor (BCM) Model and the finite differences method. The memristor circuit is investigated for sinusoidal supply current at different magnitudes - for soft-switching and hardswitching modes, respectively. The influence of the initial values of the state variables on the circuit's behaviour is presented as well. The equivalent $i-v$ and memristance-flux and the other important relationshipsof the memristor circuit are also analyzed.

Keywords: memristor; anti-parallel memristor circuit; finite-differences method; equivalent resistance

\section{ANALIZA PRZECIWRÓWNOLEGLEGO OBWODU MEMRYSTOROWEGO}

Streszczenie. Podstawowym celem niniejszego artykulu jest zaproponowanie rozszerzonego badania i komputerowej analizy przeciwrównoległego układu memrystorowego z dwoma równoważnmi elementami memrystorowymi o różnych wartościach początkowych zmiennych stanu z wykorzystaniem zmodyfikowanego modelu Boundary Condition Memristor (BCM) i metody różnic skończonych. Obwód memrystorowy jest badany dla sinusoidalnego prądu zasilania o różnych wielkościach - odpowiednio dla trybów miękkiego przełaczania i twardego przełączania. Przedstawiono również wpływ wartości początkowych zmiennych stanu na zachowanie obwodu. Analizowane sa również równoważne charakterystyki prądowo-napięciowe zależność między memrystancją i strumieniem magnetycznym oraz inne ważne cechy obwodu memrystora.

Slowa kluczowe: memrystor; przeciwrównoległy obwód memrystorowy; metoda różnic skończonych; rezystancja równoważna

\section{Introduction}

After the theoretical prediction of the memristor element by Prof. L. Chua [3] in 1971 and the physical realization of the memristor prototype by Stanley Williams in HP research labs [2] in 2008 a lot of scientific papers associated with memristors are published $[1,4,7,8]$. An anti-parallel memristor circuit with two memristor elements is analyzed in an oscillator circuit in [4] and [8]. The lack of detailed investigation of anti-parallel memristor circuits for sine-wave mode was the basic motivation for the present research. The modified linear drift memristor model proposed here is based on the BCM model [4], but for simplification, the model used here is without sensitivity voltage thresholds. For the analyses, we use an algorithm based on the finite differences method for numerical analysis. The basic purposes of our paper are to derive the main important relationships of the memristor circuit, its equivalent resistance for sine-wave current source power supply and to acquire the main results for hard-switching and soft-switching modes.

The paper is organized as follows. In Section 1 a description of the modified memristor model used for the computer simulations is proposed. In Section 2 a rigorous analysis of the anti-parallel memristor circuit is presented. The basic results from the simulations are presented and discussed in Section 3. The conclusion is shown in Section 4.

\section{A description of the used memristor model}

The modified BCM memristor model will be discussed using the titanium-dioxide memristor structure [7] given in Fig. 1. The upper region of the $\mathrm{TiO}_{2}$ structure with a length of $w$ is doped with oxygen vacancies [7]. The second sub-layer is made of pure $\mathrm{TiO}_{2}$. The length of whole memristor structure is denoted with $\mathrm{D}[4,7]$.

The normalized length of the doped layer of the memristor element, also known as the state variable $x$ could be defined with the following formula $[1,4,7]$ :

$$
x=\frac{w}{\mathrm{D}}
$$

The equivalent resistance of the memristor element could be expressed using the assumption for series linking of the doped and the un-doped regions [7]:

$$
R=R_{\text {doped }}+R_{\text {un-doped }}=\mathrm{R}_{\mathrm{ON}} x+\mathrm{R}_{\mathrm{OFF}}(1-x)
$$

where $\mathrm{R}_{\mathrm{ON}}$ and $\mathrm{R}_{\mathrm{OFF}}$ are the memristances for fully-closed and fully-open states, for $x=1$ or $x=0$, respectively [4,7].

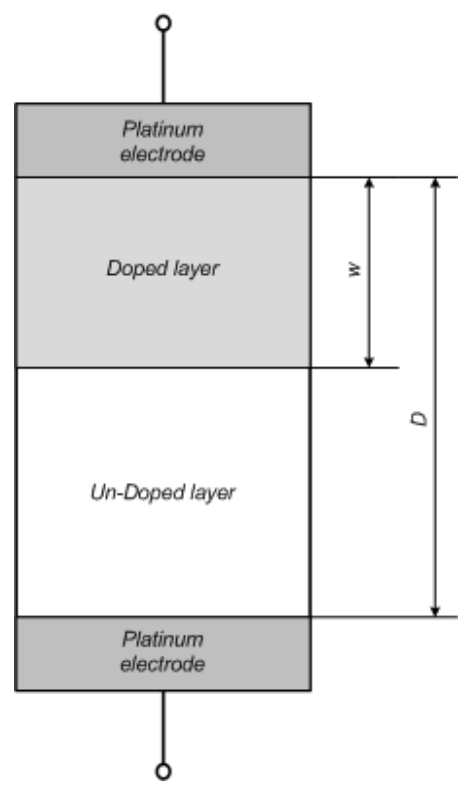

Fig. 1. Structure of the titanium dioxide memristor element

The i-v relation of the memristor element could be expressed using (2) and the state-dependent Ohm's law [2,7]:

$$
u=R i=\left[\mathrm{R}_{\mathrm{ON}} x+\mathrm{R}_{\mathrm{OFF}}(1-x)\right] i
$$

The voltage drop across the doped region of the memristor element $u_{w}$ is $[2,4,7]$ :

$$
u_{w}=R_{\text {doped }} i=\mathrm{R}_{\mathrm{ON}} x i=\mathrm{R}_{\mathrm{ON}} i \frac{w}{\mathrm{D}}
$$

The electric field intensity in the doped layer of the memristor element $\boldsymbol{E}_{w}$ is $[2,5]$ :

$$
\mathbf{E}_{\mathrm{w}}=\frac{u_{w}}{w}=i \frac{\mathrm{R}_{\mathrm{ON}}}{\mathrm{D}}
$$

The rate of moving the border between doped and un-doped regions of the element is [5, 7]:

$$
v=\frac{\mathrm{d} w}{\mathrm{~d} t}=\frac{\mathrm{d}}{\mathrm{d} t}(x \mathrm{D})=\mathrm{D} \frac{\mathrm{d} x}{\mathrm{~d} t}=\mu \mathbf{E}_{\mathrm{w}}
$$

where $\mu$ is the ionic dopant drift mobility [5, 7]. After transformations of (6) the basic differential state equation of the memristor element is derived $[4,7]$ :

$$
\frac{\mathrm{d} x}{\mathrm{~d} t}=\frac{\mu \mathrm{R}_{\mathrm{ON}}}{\mathrm{D}^{2}} i=\mathrm{k} i
$$


where $\mathrm{k}$ is a constant dependent only on memristor parameters. When we have two or more memristors in an electric circuit formula (7) has to be adapted [1, 4]:

$$
\frac{\mathrm{d} x}{\mathrm{~d} t}=\eta \frac{\mu \mathrm{R}_{\mathrm{ON}}}{\mathrm{D}^{2}} i=\eta \mathrm{k} i
$$

where $\eta$ is a polarity coefficient $[1,4]$. When the memristor element is forward-biased we have $\eta=1$. For reverse-biased memristor we have $\eta=-1$ [4]. An anti-parallel circuit with two memristors supplied by a sinusoidal current source is given in Fig. 2. The first memristor $M_{1}$ is forward-biased and the second one $\mathrm{M}_{2}$ is reverse-biased. For the circuit analysis we use a modified BCM model with linear ionic drift and without sensitivity thresholds. The BCM model switch-based algorithm is used here for representation the boundary effects [4].

The BCM model is appropriate for simulation of memristor elements both for soft-switching and hard-switching mode $[1,4,8]$. For soft-switching mode the state variable $x$ does not reach its limiting values -0 and 1 , respectively. For hardswitching the state variable $x$ reaches its boundary values and for a forward-biased memristor, if the state variable $x=0$, its value could be changed only if the current through it becomes positive $[1,4]$. If $x$ increases and becomes equal to 1 , the state variable $x$ could be changed only if the current is negative. For a reversebiased memristor operating in a hard-switching mode, if the state variable becomes with a value of $x=0$, it could be changed if the memristor current is negative. If the state variable $x$ becomes equal to 1 , it could be changed if the current is positive [4].

\section{Analysis of the memristor circuit}

The memristor circuit under analysis is given in Fig. 2 . It contains two equivalent memristors with different initial values of the state variables $x_{1}$ and $x_{2}$. The state equations are:

$$
\begin{aligned}
& \frac{\mathrm{d} x_{1}}{\mathrm{~d} t}=\eta_{1} \mathrm{k} i_{1}=\mathrm{k} i_{1} \\
& \frac{\mathrm{d} x_{2}}{\mathrm{~d} t}=\eta_{2} \mathrm{k} i_{2}=-\mathrm{k} i_{2}
\end{aligned}
$$

According to the Kirchhoff Current Law we have [2]:

$$
j_{e}(t)=i_{1}+i_{2}
$$

Using (2) we obtain the equivalent resistance $R_{12}$ of the parallel connection of the memristors [2]:

$$
\begin{aligned}
& R_{1}=\left(\mathrm{R}_{\mathrm{ON}}-\mathrm{R}_{\mathrm{OFF}}\right) x_{1}+\mathrm{R}_{\mathrm{OFF}} \\
& R_{2}=\left(\mathrm{R}_{\mathrm{ON}}-\mathrm{R}_{\mathrm{OFF}}\right) x_{2}+\mathrm{R}_{\mathrm{OFF}} \\
& \Delta \mathrm{R}=\mathrm{R}_{\mathrm{ON}}-\mathrm{R}_{\mathrm{OFF}} \\
& R_{12}=\frac{R_{1} R_{2}}{R_{1}+R_{2}}=\frac{\left(\mathrm{R}_{\mathrm{OFF}}+\Delta \mathrm{R} x_{1}\right)\left(\mathrm{R}_{\mathrm{OFF}}+\Delta \mathrm{R} x_{2}\right)}{2 \mathrm{R}_{\mathrm{OFF}}+\Delta \mathrm{R}\left(x_{1}+x_{2}\right)}
\end{aligned}
$$

The voltage drop across the memristors is [2]

$$
u=j_{e}(t) R_{12}=j_{e}(t) \frac{\left(\mathrm{R}_{\mathrm{OFF}}+\Delta \mathrm{R} x_{1}\right)\left(\mathrm{R}_{\mathrm{OFF}}+\Delta \mathrm{R} x_{2}\right)}{2 \mathrm{R}_{\mathrm{OFF}}+\Delta \mathrm{R}\left(x_{1}+x_{2}\right)}
$$

The currents flowing through the memristors are [2]:

$$
\begin{aligned}
& i_{1}=j_{e}(t) \frac{\left(\mathrm{R}_{\mathrm{OFF}}+\Delta \mathrm{R} x_{2}\right)}{2 \mathrm{R}_{\mathrm{OFF}}+\Delta \mathrm{R}\left(x_{1}+x_{2}\right)} \\
& i_{2}=j_{e}(t) \frac{\left(\mathrm{R}_{\mathrm{OFF}}+\Delta \mathrm{R} x_{1}\right)}{2 \mathrm{R}_{\mathrm{OFF}}+\Delta \mathrm{R}\left(x_{1}+x_{2}\right)}
\end{aligned}
$$

A sinusoidal current source is used for the computer simulation. Using (9), (10) and (11), the KCL and the finitedifferences method a pseudo-code is created:

A pseudo-code algorithm for simulations of the anti-parallel memristor circuit with two memristors:

1. begin procedure eta $1=1$; eta $2=-1$; Jem=1e-3; $f=40$; psiu $=$ deg $2 \operatorname{rad}(-60)$;

2. Ron=100; Roff $=16000$; deltaR=Ron-Roff; $m u=1 \mathrm{e}-12$;

3. $\mathrm{D}=10 \mathrm{e}-9 ; \mathrm{k}=\left(\mathrm{mu}^{*} \mathrm{Ron}\right) /\left(\mathrm{D}^{\wedge} 2\right) ; \mathrm{x} 01=0.3 ; \mathrm{x} 02=0.7 ; \mathrm{xmin}=0$; $x \max =1$;

4. [je,t,deltat,tmin,tmax, $\mathrm{N}]=$ sine_gen(Jem,f,psiu);
5. $\mathrm{n}=1: 1: \mathrm{N}+1 ; \%$ sample vector

6. $[x 1, x 2]=$ memr_x_antipar_MM(je,deltat,tmin,tmax,... $\mathrm{x} 01, \mathrm{x} 02, \mathrm{k}, \mathrm{Roff}, \mathrm{deltaR}, \mathrm{xmin}, \mathrm{xmax})$;

7. $\mathrm{R} 1=$ deltaR $* x 1+$ Roff; $\mathrm{R} 2=\operatorname{deltaR} * x 2+$ Roff; Req $=$ $(\mathrm{R} 1 . * \mathrm{R} 2) . /(\mathrm{R} 1+\mathrm{R} 2)$;

8. $\mathrm{u}=$ je.*Req; iM1 = u./R1; iM2 = u./R2; flux = integr(u,deltat,tmin,tmax);

9. function $[\mathrm{u}, \mathrm{t}, \mathrm{deltat}, \mathrm{tmin}, \mathrm{tmax}, \mathrm{N}]=\mathrm{sine}$ _gen(um,f,psiu) Steady state sine analysis

10. $\mathrm{T}=1 / \mathrm{f} ; \mathrm{tmin}=0 ; \operatorname{tmax}=8 * \mathrm{~T} ;$ deltat $=(\operatorname{tmax}-\mathrm{tmin}) / 1 \mathrm{e} 6$;

11. $\mathrm{t} 1=$ tmin $:$ deltat $:$ tmax; omega $=2 *$ pi*f; $\mathrm{f} 1=$ um*sin $($ omega*t1 + psiu);

12. $\mathrm{u}=\mathrm{f} 1 ; \mathrm{t}=\mathrm{t} 1 ; \mathrm{N}=$ tmax/deltat; end function

13. function $[\mathrm{x} 1, \mathrm{x} 2]=$ memr_ $\mathrm{x}_{-}$antipar_MM (je, deltat, tmin, tmax, $\mathrm{x} 01, \mathrm{x} 02, \mathrm{k}$, Roff,deltaR,xmin,xmax)

14. $\mathrm{N}=(\operatorname{tmax}-\mathrm{tmin}) /$ deltat; $\%$ number of samples; $\mathrm{n}=1: 1: \mathrm{N}+1$; $\%$ obtaining $\mathrm{x} 1$ and $\mathrm{x} 2 ; \mathrm{x} 1=[] ; \mathrm{x} 2=[]$;

15. for $\mathrm{n}=1, \quad \mathrm{x} 11=\mathrm{x} 01 ; \quad \mathrm{x} 22=\mathrm{x} 02$; end

16. for $n=2: 1: N+1$

17. $A=(\operatorname{deltaR} *(x 11(n-1)+x 22(n-1))+(2 * \operatorname{Roff})) ; \%$ in the denominator

18. $\mathrm{x} 11(\mathrm{n})=\mathrm{x} 11(\mathrm{n}-1)+((\mathrm{k} * \mathrm{je}(\mathrm{n}-1) * \operatorname{deltat} *(\mathrm{deltaR} *$ $\mathrm{x} 22(\mathrm{n} 1)+\mathrm{Roff})) / \mathrm{A})$;

19. $\mathrm{x} 22(\mathrm{n})=\mathrm{x} 22(\mathrm{n}-1)-((\mathrm{k} * \mathrm{je}(\mathrm{n}-1) * \operatorname{deltat} *(\operatorname{deltaR} *$ $\mathrm{x} 11(\mathrm{n}-1)+\mathrm{Roff})) / \mathrm{A})$;

20. $\%$ boundary condition switching $x 11$

21. if $\mathrm{x} 11(\mathrm{n})<=\mathrm{xmin} \& \&$ je $(\mathrm{n})<=0$

22. $\mathrm{x} 11(\mathrm{n})=\mathrm{xmin}$;

23. elseif $x 11(n)>=x \max \& \&$ je $(n)>=0$

24. $x 11(n)=x \max$

25. else $\mathrm{x} 11(\mathrm{n})=\mathrm{x} 11(\mathrm{n}-1)+((\mathrm{k} * \mathrm{je}(\mathrm{n}-1) *$ deltat $*(\operatorname{deltaR} *$ $\mathrm{x} 22(\mathrm{n}-1)+$ Roff) $) / \mathrm{A})$; end

26. $\%$ boundary condition switching $\mathrm{x} 22$

27. if $x 22(n)<=x \min \& \&$ je $(n)>=0$

28. $x 22(n)=x \min$;

29. elseif $x 22(n)>=x \max \& \&$ je $(n)<=0$

30. $x 22(n)=x m a x ;$ else $x 22(n)=x 22(n-1)-((k * j e(n-1)$ $*$ deltat*(deltaR*x11(n-1)+Roff) $) / \mathrm{A}) ; \quad$ end

31. end $\mathrm{x} 1=[\mathrm{x} 1 \mathrm{x} 11] ; \mathrm{x} 2=[\mathrm{x} 2 \mathrm{x} 22]$;

end function; end procedure.

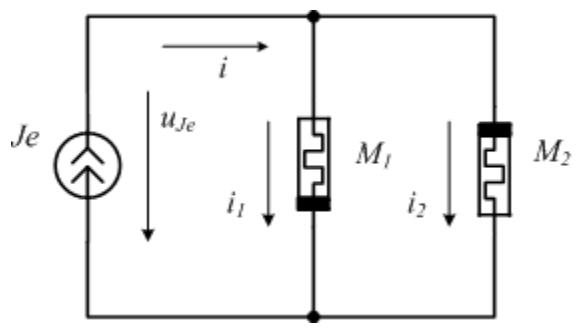

Fig. 2. An anti-parallel memristor circuit under analysis

\section{Results by the computer simulation}

The anti-parallel memristor circuit given in Fig. 2 is investigated for soft-switching and hard-switching modes, respectively $[1,4]$ and its computer simulations were made in MATLAB environment [2, 4, 6]. An additional simulation obtained by SIMSCAPE [8] confirms the results given below.

\subsection{Soft-switching mode}

For analysis of the anti-parallel memristor circuit at softswitching mode we use a sinusoidal current source with the following signal: $j_{e}(t)=0.1 \cdot \sin \left(2 \cdot \mathrm{pi} \cdot 40 \cdot t-60^{\circ}\right), \mathrm{mA}$. The time diagrams of the source current and the voltage drop across the parallel-connected memristors are presented in Fig. 3. It is obvious that the source current is sinusoidal but the voltage drop across the memristors has a non-sinusoidal form due to the nonlinearity of the memristor elements [7]. 

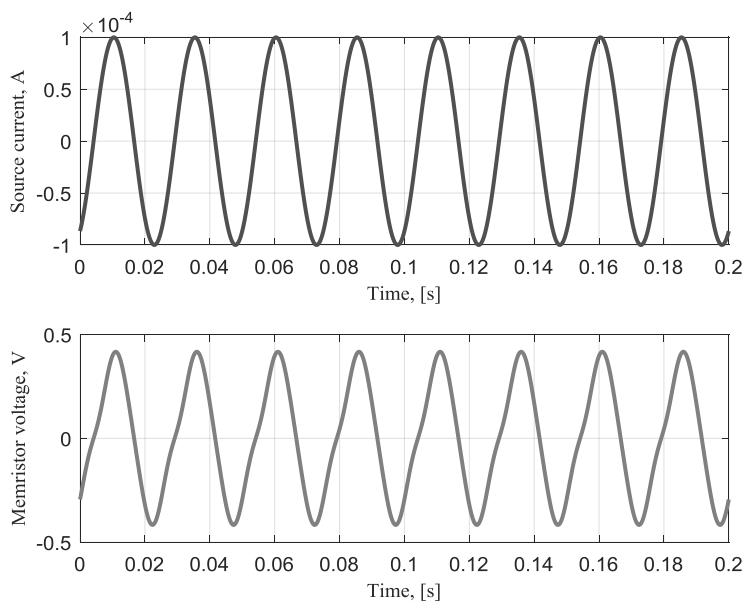

Fig. 3. Time diagrams of the source current and voltage drop across the memristors $M_{1}$ and $M_{2}$ for soft-switching mode

The time diagrams of the state variables $x_{1}$ and $x_{2}$ for the memristor elements are given in Fig. 4. It is clear that the state variables do not reach their limiting values. When the state variable $x_{1}$ increases then the state variable $x_{2}$ decreases due to the anti-parallel biasing.

The state-flux relationships of the memristors $\mathrm{M}_{1}$ and $\mathrm{M}_{2}$ are presented in Fig. 5 and Fig. 6, respectively. They are single-valued curves. Due to the anti-parallel connection they have different signs of their derivatives - the first is an increasing curve but the second is a monotonically decreasing curve. When $x_{1}$ increases then the state variable $x_{2}$ decreases, and vice versa.

The time diagrams of the memristances of the elements are presented in Fig. 7. Due to the anti-parallel connection when $R_{I}$ increases then $R_{2}$ decreases, and vice versa.

The time diagram of the equivalent resistance $R_{12}$ of the antiparallel connection is presented in Fig. 8. It is obvious that the parallel resistance of the memristor connection is a timedependent non-sinusoidal function.

The memristance-flux relationship of the memristor parallel connection is presented in Fig. 9. It is a single-valued function with a local maximum which is obtained for a specific value of $R_{l}$ and $R_{2}$ according (11).

The current-voltage relationships of the memristors $\mathrm{M}_{1}$ and $\mathrm{M}_{2}$ are presented in Fig. 10 and Fig. 11. It is clear that the current intensity for the second memristor $\mathrm{M}_{2}$ is higher than the current through the memristor $M_{1}$. This fact is due to the different initial values of the state variables and the different biasing polarities.
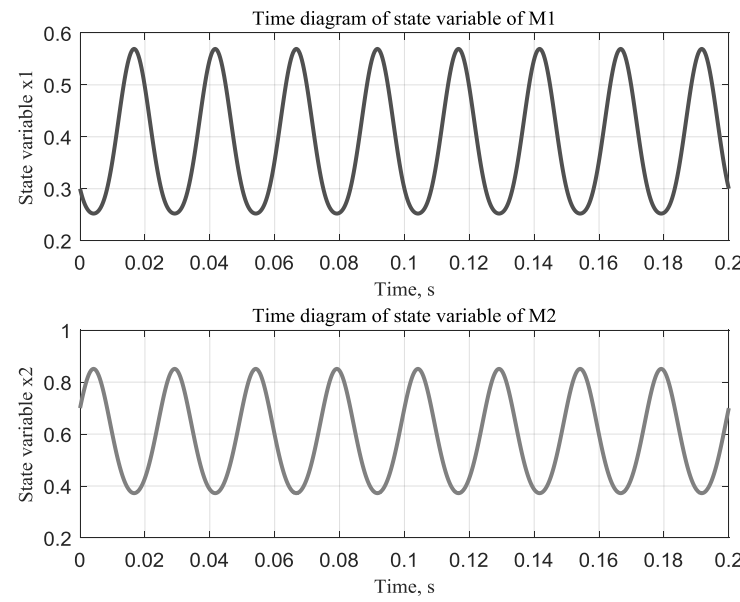

Fig. 4. Time diagrams of the state variables $x_{1}$ and $x_{2}$ of the memristors for softswitching mode

The equivalent current-voltage relationship of the memristor parallel connection is presented in Fig. 12. It is a pinched hysteresis loop and it shows us that in this case the parallel connection of two anti-parallel memristor elements has a behaviour of a single memristor element.

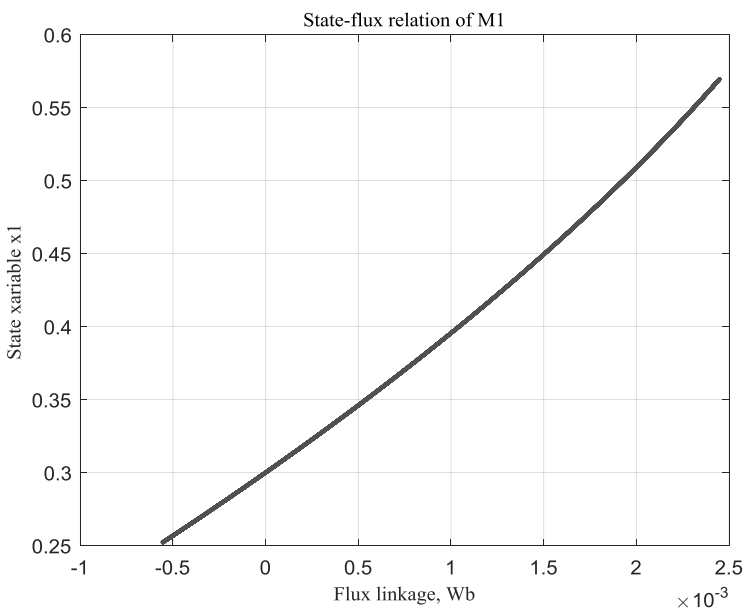

Fig. 5. State-flux relationship of the memristor $M_{1}$ for soft-switching mode

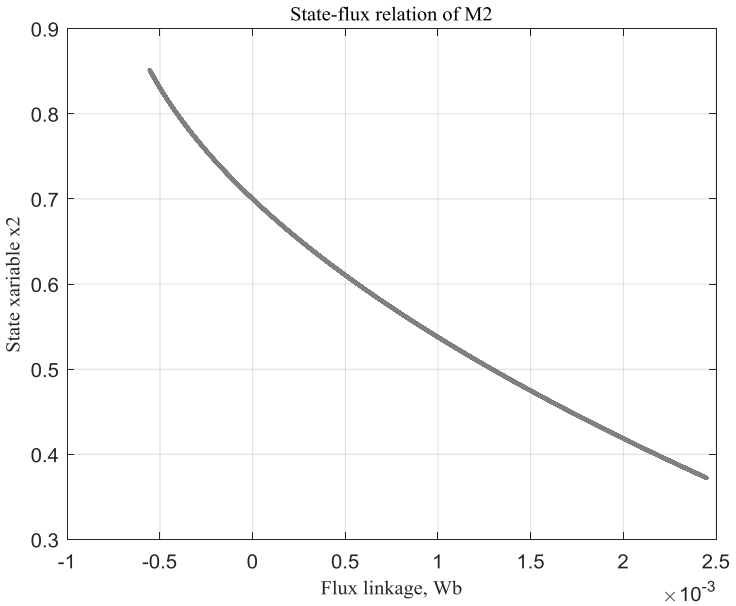

Fig. 6. State-flux relationship of the memristor $\mathrm{M}_{2}$ for soft-switching mode
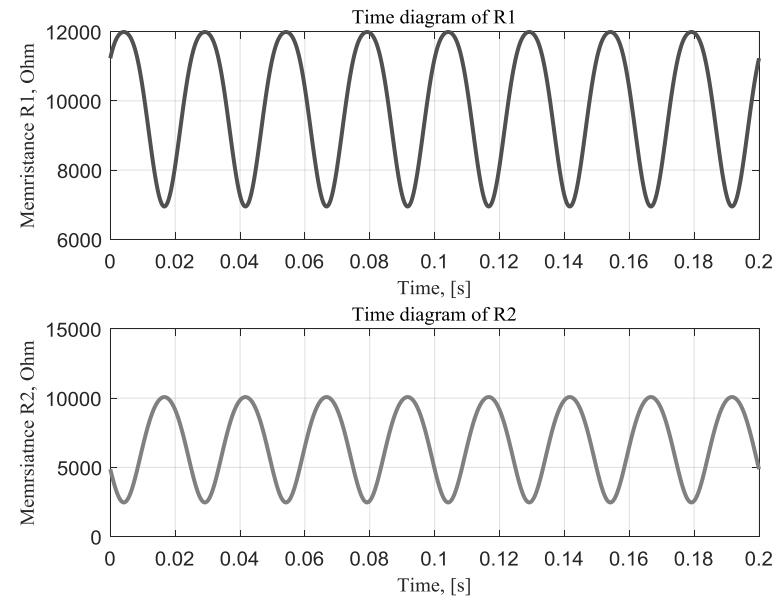

Fig. 7. Time diagrams of the memristances of the elements of the anti-parallel memristor circuit for soft-switching mode

\subsection{Hard-switching mode}

For analysis of the anti-parallel memristor circuit at hardswitching mode we use a sinusoidal current source with the following signal: $j_{e}(t)=1 \cdot \sin \left(2 \cdot \mathrm{pi} \cdot 40 \cdot t-60^{\circ}\right), \mathrm{mA}$. The time diagrams of the source current and the voltage drop across the memristors are presented in Fig. 13. It is obvious that the source current is sinusoidal but the voltage drop across the memristors has highly a non-sinusoidal form due to the extended memristor 
nonlinearity for hard-switching mode. The time diagrams of the state variables for hard-switching mode are presented in Fig. 14. It is clear that the state variables reach their limiting values -0 and 1 . If $x_{1}$ has a value of 1 then $x_{2}$ is equal to 0 , and vice versa.

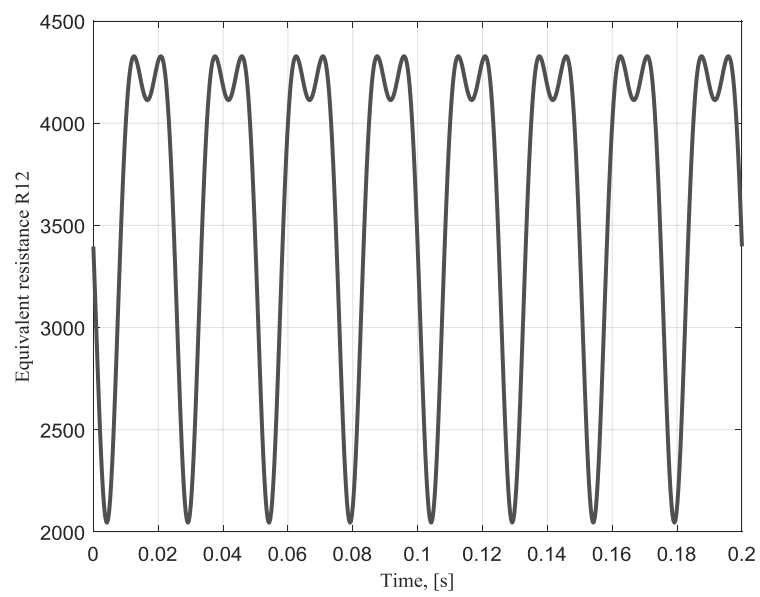

Fig. 8. Time diagram of the equivalent resistance of the anti-parallel memristor circuit for soft-switching mode

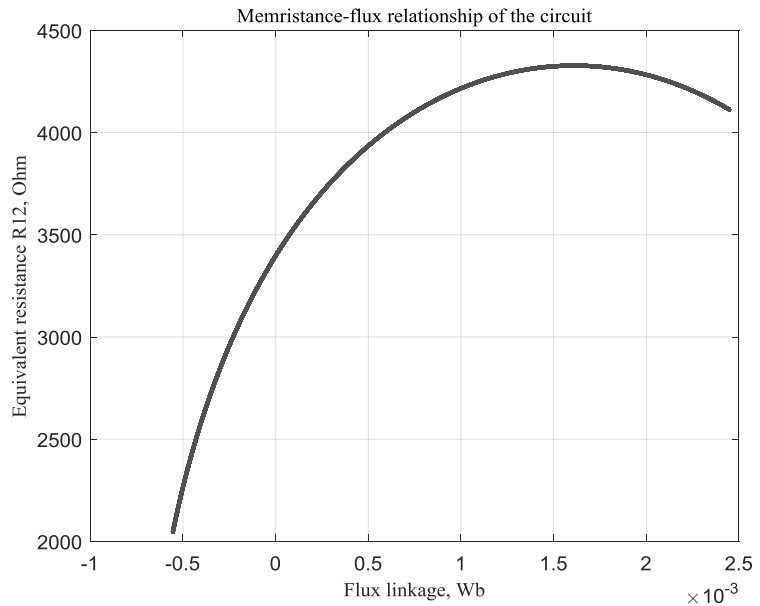

Fig. 9. Memristance-flux relationship of the anti-parallel memristor circuit for softswitching mode

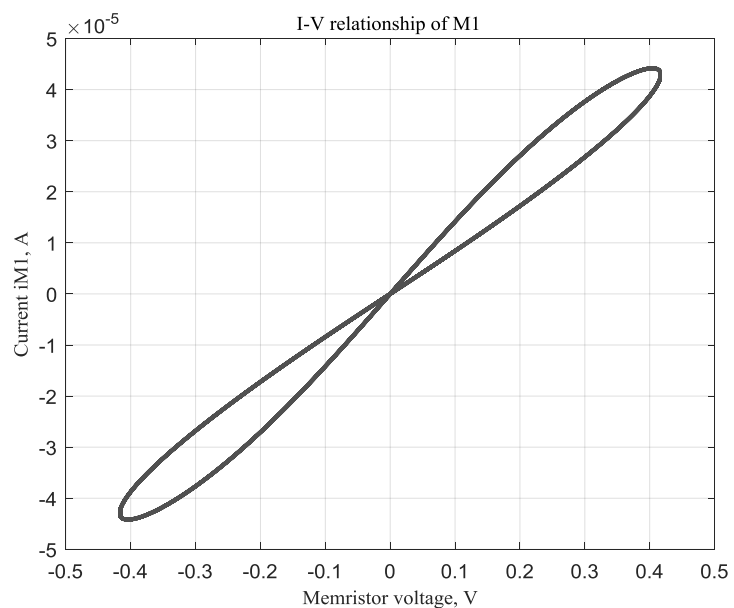

Fig. 10. Current-voltage relationship of the first memristor $M_{I}$ for soft-switching

The state-flux relationships of the memristor elements are presented in Fig. 15. It is clear that they are multi-valued hysteresis curves. Due to the different biasing polarities of the memristor elements their slope and respectively the first derivative are different to each other. When $x_{1}$ increases to 1 then the state variable $x_{2}$ decreases to 0 , and vice versa. The memristance-flux relationship of the anti-parallel memristor connection is given in Fig. 16. It is a multi-valued hysteresis curve with a local maximum. After comparison of Fig. 15 and Fig. 16 it could be concluded that the diagram presented in Fig. 16 is derived using the state-flux relationships of the memristors for hard-switching. The memristances of the elements are reverse proportional to the respective state variables.

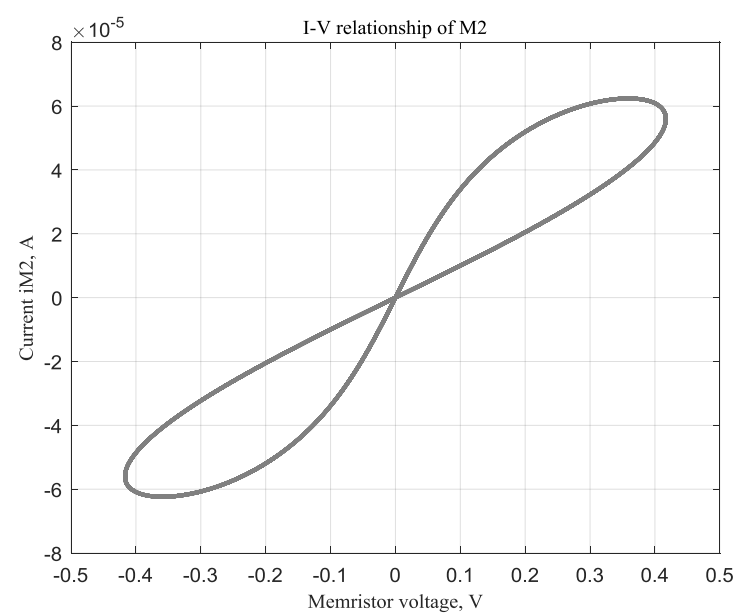

Fig. 11. Current-voltage relationship of the first memristor element $M_{2}$ for softswitching mode

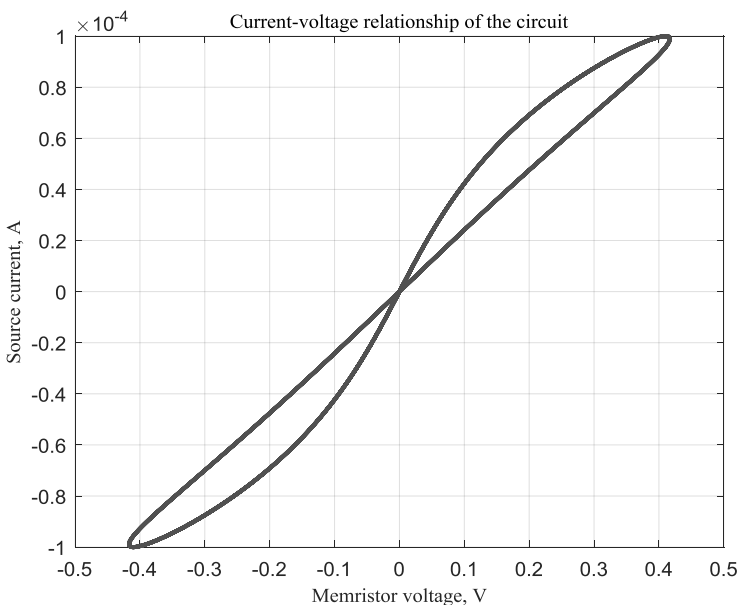

Fig. 12. Current-voltage relationship of the whole anti-parallel memristor circuit for soft-switching mode
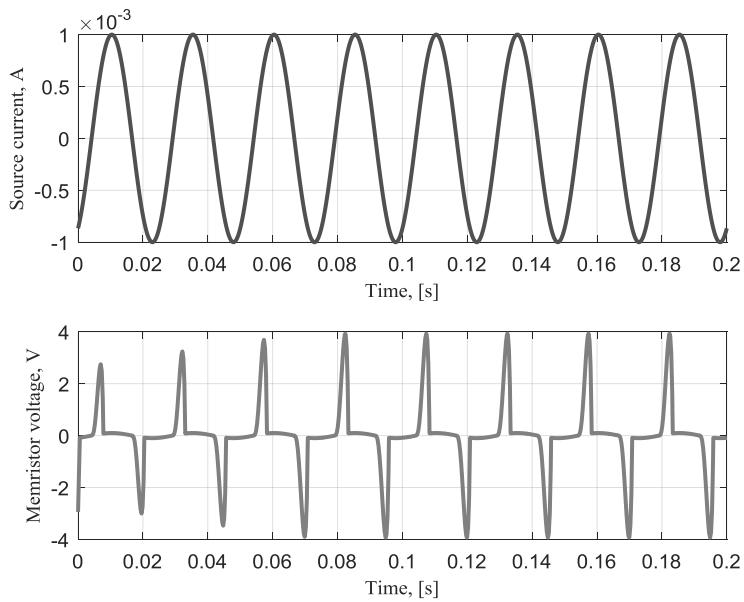

Fig. 13. Time diagrams of the source current and the voltage drop across the memristors $M_{l}$ and $M_{2}$ for hard-switching mode

The time diagrams of the memristances of the memristor elements are presented in Fig. 17. It is clear that their resistances 
reach their limiting values - $100 \mathrm{Ohms}$ and $16 \mathrm{kOhms}$, respectively, in the same time excluding the transition time intervals between the fully open and fully closed states. The time diagram of the equivalent resistance of the anti-parallel memristor connection is presented in Fig. 18. It is understandable that for more of the time intervals the first or the second memristor operates in a hard-switching mode and has its minimal resistance. Due to this fact the equivalent resistance of the anti-parallel memristor circuit for the long-time intervals has also its minimal value which is lower than $100 \mathrm{Ohms}$.
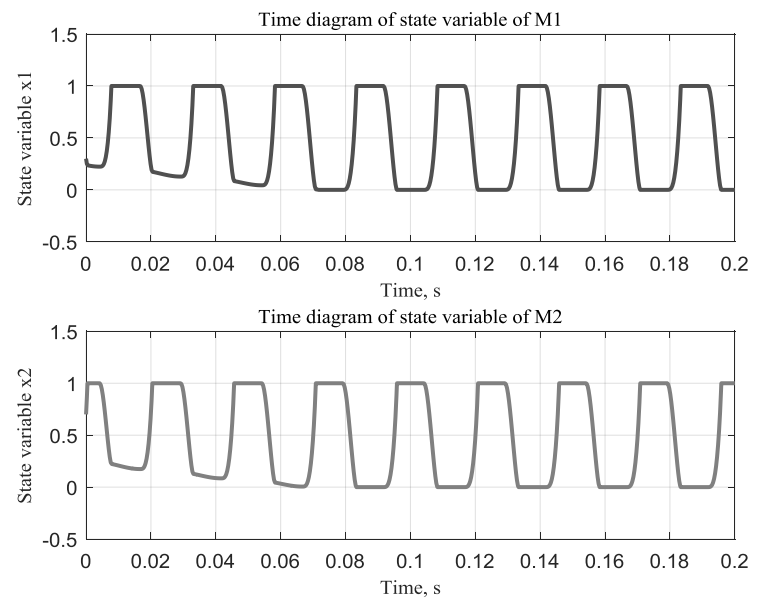

Fig. 14. Time diagrams of the state variables $x_{1}$ and $x_{2}$ of the memristor elements for hard-switching mode
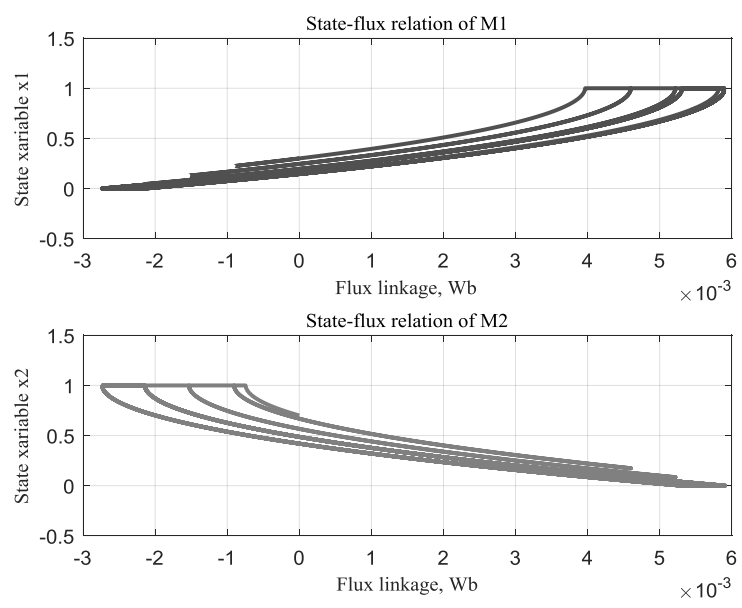

Fig. 15. State-flux relationships of the memristor elements $M_{1}$ and $M_{2}$ for hardswitching mode

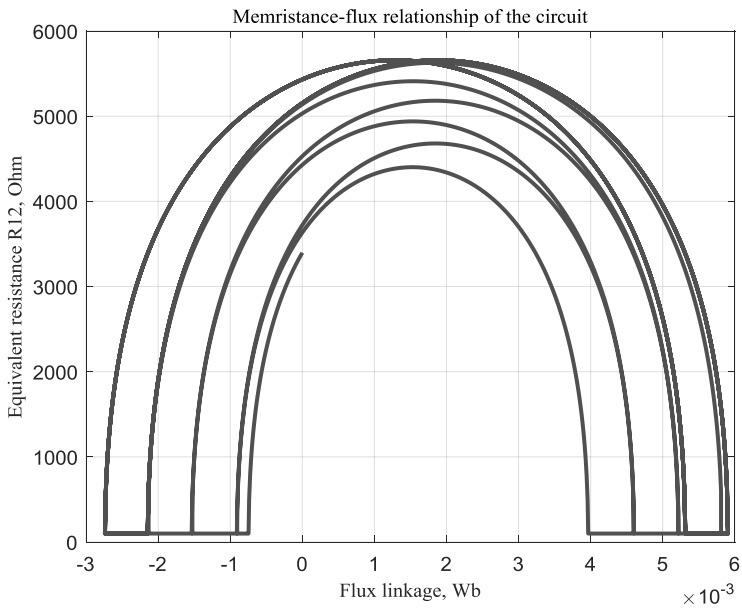

Fig. 16. Memristance-flux relationship of the whole anti-parallel memristor circuit for hard-switching mode
The current-voltage relationships of the memristor elements are presented in Fig. 19. These curves in the present case are antisymmetrical. For hard-switching mode the memristors have rectifying effect and their behaviour is similar to the operation of the semiconductor diodes. When the first memristor is reaching a fully-open state in the same time interval the second memristor reaches its fully-closed state, and vice-versa.

The current-voltage characteristic of the equivalent antiparallel memristor circuit is given in Fig. 20. Due to the antiparallel connection of the memristor elements the equivalent memristor circuit has a symmetrical pinched multi-valued i-v relationship and it have not rectifying properties in this case.
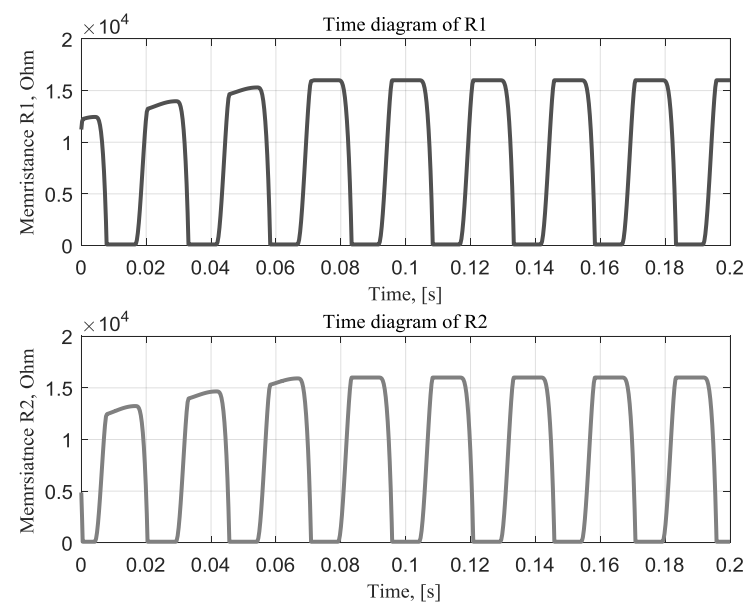

Fig. 17. Time diagrams of the memristances of the elements of the anti-parallel memristor circuit for hard-switching mode

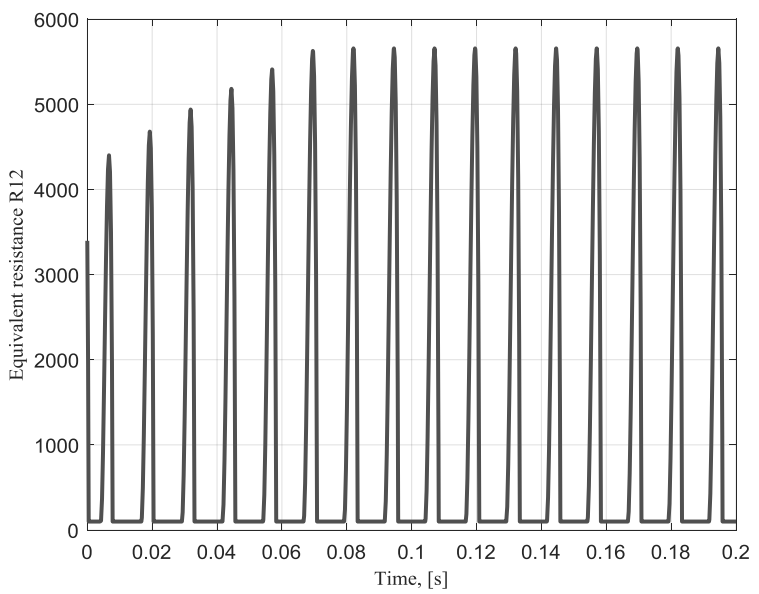

Fig. 18. Time diagram of the equivalent resistance of the anti-parallel memristor circuit for hard-switching mode

Due to the high nonlinearity of the memristor elements for hard-switching mode the respective memristance-flux relationships and the current-voltage characteristics are multivalued functions. The maximal values of the equivalent memristance of the anti-parallel memristor circuit are from $4400 \mathrm{Ohms}$ to $5600 \mathrm{Ohms}$. When the total resistance of the antiparallel memristor circuit under analysis obtain its maximal values then both the memristor elements are operating near to fullyclosed state. When the equivalent resistance of the investigated anti-parallel memristor circuit is lower than $100 \mathrm{Ohms}$ then at least one of the memristor elements is in a fully-closed state and the respective state variable is equal to 0 . 

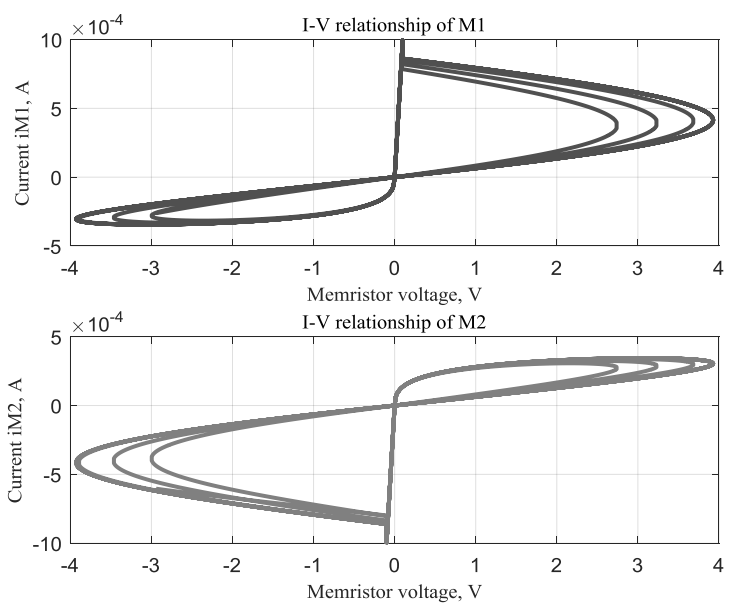

Fig. 19. Current-voltage relationship of the first memristor element $M_{I}$ for hardswitching mode

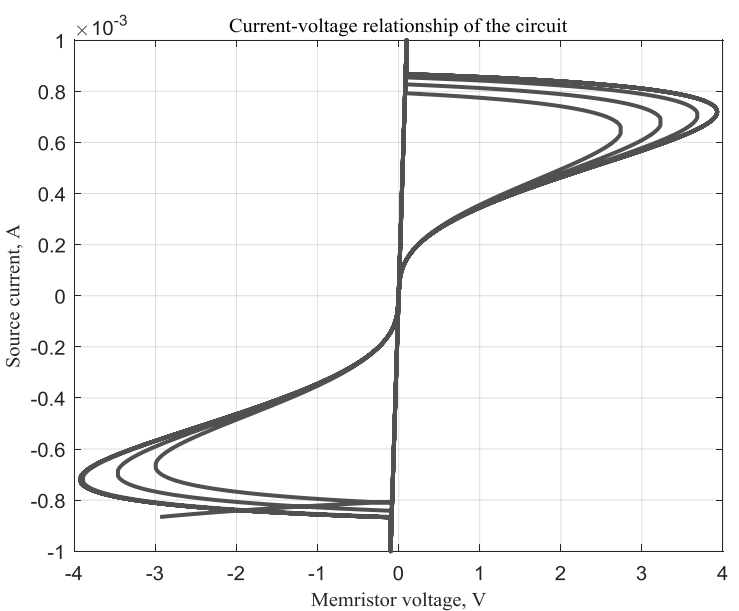

Fig. 20. Current-voltage relationship of the whole anti-parallel memristor circuit for hard-switching mode

\section{Conclusion}

After finishing the analytical investigations and the computer simulations of the anti-parallel memristor circuit several conclusions could be completed. The computer analysis results confirm the theoretical investigations made in Section 2. The influence of the current source has different effect on the two memristors due to their different polarity biasing. For a sinusoidal source current signal with a magnitude of $0.1 \mathrm{~mA}$ both the memristors operate in a soft-switching mode. For soft-switching mode if one of the memristor has increasing conductance in the same time the conductance of the other memristor decreases. The equivalent memristor circuit has a pinched single-valued hysteresis of the current-voltage relationship and in the present case it behaves like a single memristor element. For a sinusoidal signal with a magnitude value of $1 \mathrm{~mA}$ both the memristor elements operate in a hard-switching mode. In many time intervals with a relatively long duration the first memristor is in a fullyopen state while the second memristor is in a fully-closed state, and vice versa. Then the anti-parallel memristor circuit has minimal resistance lower than 100 Ohms. In the other time intervals both the memristors operate in an active mode so the state variables are in the interval $(0,1)$. The equivalent currentvoltage relationship of the whole anti-parallel memristor circuit is a symmetrical multi-valued curve despite of the fact that each of the memristor elements in the anti-parallel circuit has an antisymmetrical single-valued current-voltage relationship. Then the equivalent behaviour of the anti-parallel memristor circuit is different from the operation of the rectifying elements. For hardswitching the memristor circuit has a high nonlinearity.

\section{Acknowledgements}

The research is supported by national Co-financing (contract № ДКОСТ01/14) of COST Action № IC1401 MemoCIS.

\section{References}

[1] Ascoli A., Corinto F., Tetzlaff R.: Generalized Boundary Condition Memristor Model. Int. J. Circ. Theor. Appl. 44/2016, 60-84.

[2] Brandisky K., Georgiev Z., Mladenov V., Stancheva R.: Theoretical Electrical Engineering - Part 1 \& 2, KING Publishing House, Sofia 2005.

[3] Chua L.O.: Memristor - The Missing Circuit Element. IEEE Trans. on Circuit Theory CT-18/1971, 507-519.

[4] Corinto F., Ascoli A.: A Boundary Condition-Based Approach to the Modelling of Memristor Nanostructures. IEEE Transactions on Circuits and Systems - I, Regular Papers 59(11)/2012, 2713-2726.

[5] Hristov M., Vassileva T., Manolov M.: Semiconductor elements. New knowledge Publishing House, Sofia 2007.

[6] MATLAB - Version 7.12.0.635 (R2011a) User's Guide. The MathWorks, Inc.

[7] Strukov D.B., Snider G.S., Stewart D.R., Williams R.S.: The missing memristor found. Nature 453(06932)/2008, 80-83.

[8] Walsh A., Carley R., Feely O., Ascoli A: Memristor circuit investigation through a new tutorial toolbox. European Conference on Circuit Theory and Design (ECCTD) - Germany, 2013, 1-4.

\section{Prof. Valeri Mladenov}

e-mail: valerim@tu-sofia.bg

Prof. Mladenov has received his Ph.D. in Electrical Engineering from Technical University of Sofia in 1993. He is a Senior Member of IEEE and has awarded for dedication and contributions. $\mathrm{He}$ has written more than 300 papers in professional journals and conferences. His research interests are in the field of nonlinear systems, neural networks, artificial intelligence, applied mathematics and signal processing. He serves as a reviewer for a number of scientific journals.

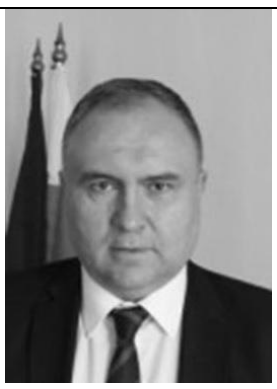

\section{Ph.D. Stoyan Kirilov}

e-mail: s_kirilov@tu-sofia.bg

Dr. Kirilov has graduated in Telecommunications in 2010 and he receives his Ph.D. from Technical University of Sofia in Theoretical Electrical Engineering in 2014. Since 2016 he is a Chef Assistant Professor in the same institution. His main scientific and research interests are associated with simulations and modeling of memristors and memristive circuits, electronic elements and devices. $\mathrm{He}$ has been a reviewer in several scientific conferences - ICEST, ECCTD.

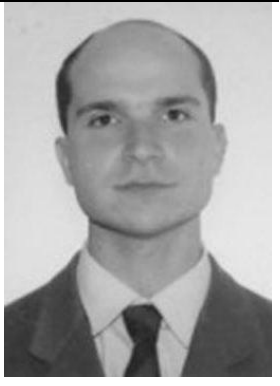

otrzymano/received: 08.12.2017 